\title{
CONCEPÇÕES SOBRE A INTERAÇÃO COM MORADORES DE RESIDÊNCIAS TERAPÊUTICAS
}

\author{
CONOCIENDO LA INTERACCIÓN CON LOS RESIDENTES DE LAS
} RESIDENCIAS TERAPÉUTICAS

CONCEPTIONS ABOUT THE INTERACTION WITH RESIDENTS OF THERAPEUTICAL RESIDENCES

http://dx.doi.org/10.1590/1807-03102015v28n1p162

Pedro Machado Ribeiro Neto e Luziane Zacché Avellar Universidade Federal do Espírito Santo, Vitória/ES, Brasil

\section{RESUMO}

Objetivamos conhecer as concepções de habitantes de um bairro onde se localizam Residências Terapêuticas (RTs) sobre a interação com os moradores desses serviços, e analisamos com o auxílio da Teoria da Identidade Social e da Teoria das Representações Sociais. Norteamos os procedimentos metodológicos com base na perspectiva etnográfica. Os participantes conhecem os moradores das RTs por apelidos, pelo nome e "de vista", sobretudo a partir da presença destes em estabelecimentos comerciais. A circulação dos moradores pelos espaços públicos do bairro possibilitou o diálogo com os participantes, contudo, restrito aos encontros de passagem: "A gente passa, oi prá lá, oi prá cá". A criação de vínculos entre participantes e moradores coexiste com representações sociais que sustentam uma limitação destes para o diálogo. A "limitação" possui função específica, relacionada aos processos de constituição identitária. É preciso ultrapassar o âmbito dos encontros fortuitos, criando laços mais demorados entre a loucura e a esfera pública.

Palavras-chave: residência terapêutica; grupo; desinstitucionalização; representações sociais; identidade social.

\section{RESUMEN}

Se investigan las concepciones de los habitantes de un barrio que tiene residencias terapéuticas, así como la interacción con los residentes. El análisis lo realizaremos con la ayuda de la Teoría de la Identidad Social y la Teoría de las Representaciones Sociales. Los procedimientos metodológicos serán guiados desde la perspectiva etnográfica. Los participantes conocen los residentes por su nombre y "de vista", especialmente con la presencia de éstos en los establecimientos comerciales. El movimiento de los residentes en el barrio favorece este diálogo con los participantes, pero esta conversación se limita a los encuentros casuales. La creación de vínculos entre los participantes y residentes conviven con representaciones sociales que sugieren una limitación de éstos para el diálogo. La "limitación" tiene una función específica relacionada con los procesos de construcción de identidad. Debemos ir más allá del ámbito de los encuentros casuales, es necesario fortalecer esta interacción en el espacio público.

Palabras clave: residencia terapéutica; grupo; desinstitucionalización; representaciones sociales; identidad social.

\begin{abstract}
We investigated the conceptions of inhabitants of a neighborhood that has Therapeutic Residences (RTs) about the interaction with residents of RTs, and analyzed with the aid of social identity theory and the theory of social representations. The methodological procedures are guided by ethnographic perspective. Participants know the residents by name and "by sight", especially with the presence of these in commercial establishments. The movement of residents on the neighborhood has favored the participants for this dialogue, but this conversation was restricted to brief encounters: "we walk by, say hi here and there". The creation of linkages between participants and residents coexists with the representations that enable the lack of dialogue in everyday interaction. The social representation of the RTs dwellers as "limited" have a specific and important function to the participants, related to the social identity. Therefore, it is necessary to strengthen the possibility for this interaction in public space.
\end{abstract}

Keywords: therapeutical residences; group; deinstitutionalization; social representations; social identity. 


\section{Introdução}

Abordaremos as concepções sociais sobre a interação com moradores de Residências Terapêuticas (RTs) a partir da visão de habitantes de um bairro que recebe três RTs. Tratam-se de serviços que se constituem como moradias destinadas aos ex-internos de hospitais psiquiátricos que perderam os laços sociais e familiares devido ao período de internação, com objetivos de proporcionar o convívio social, os laços afetivos e a reinserção social, isto é, sua reintegração à vida comunitária (Lei no 10.216/ 2001; Ministério da Saúde, 2011; Portaria $n^{\circ}$ 106/ 2000).

Consideramos que a reinserção social dos moradores de RTs implica sua circulação e participação no cotidiano das comunidades. Nesse sentido, entendemos comunidade como: "um espaço intermediário que nos oferece os recursos simbólicos e materiais para a vivência da dialética entre o singular e o mundo social" (Jovchelovitch, 2008, p. 127). Assim, a interação dos moradores de RTs na esfera pública e a participação nas decisões do dia a dia demandam essencialmente a comunicação com os outros atores sociais (Guareschi, 2002; Jovchelovitch, 2008; Portaria ${ }^{\circ}$ 3.090/2011; Rotelli, Leonardis, \& Mauri, 1986; Wachs, Jardim, Paulon, \& Resende, 2010).

Elaboramos este estudo com o objetivo de conhecer e analisar as concepções sociais acerca da interação estabelecida com moradores de RTs, mais especificamente, investigamos as concepções sociais sobre os moradores, a conversa cotidiana e os encontros na esfera pública. No sentido de responder aos objetivos propostos, partimos das concepções de habitantes de um bairro que recebe três RTs e lançamos as seguintes questões, as quais nortearam o roteiro de entrevista: quais são as suas concepções sobre os moradores das RTs? Os moradores das RTs são conhecidos pelos participantes? Existem momentos de diálogo entre participantes e moradores das RTs? E como os participantes concebem os encontros e a conversa com moradores das RTs nos espaços públicos do bairro?

Para nos auxiliar no debate e na análise das concepções sociais a respeito da interação com os moradores de RTs, nos apropriamos da Teoria da Identidade Social (TIS) (Tajfel, 1982, 1983), como também, utilizamos a Teoria das Representações Sociais (TRS) (Jodelet, 2005, 2009; Jovchelovitch, 1998, 2004, 2008; Moscovici, 2012; Palmonari, 2009).

\section{Desinstitucionalização italiana, representações sociais e identidade social}

A experiência de desinstitucionalização italiana foi fundamental para as políticas brasileiras de saúde mental. No processo italiano, o fechamento do hospital psiquiátrico possibilitou o cuidado nos espaços da cidade, por meio da criação de serviços nas comunidades, com a ênfase das ações de saúde mental voltadas para a "reprodução social" do indivíduo, visando à produção de vida, de sociabilidade. Novos códigos foram criados, com destaque para o termo "hóspede" em substituição a "paciente", usado para os ex-internos que, após a alta hospitalar, permaneciam em necessidade de proteção ou moradia antes da sua inserção plena no contexto social (Del Giudice, 1998; Rotelli, Leonardis, \& Mauri, 1986;).

Nesse sentido, as trocas afetivas dos moradores das RTs, estabelecidas nos espaços públicos, tornam-se essenciais para os movimentos de desinstitucionalização e reinserção social. De modo a aprofundar esta relação entre as RTs e a esfera pública, nos fundamentamos em Jovchelovitch (2008) e entendemos que:

Espaços públicos são pontos de encontro, territórios de conexão e comunicação, cuja principal característica é produzir visibilidade, de modo que questões de interesse comum possam emergir e que a pluralidade de perspectivas que constitui a comunidade possa ser trabalhada e resolvida. (Jovchelovitch, 2008, p. 147)

Acreditamos que algumas teorias da Psicologia Social podem contribuir com a discussão sobre a interação social com moradores de RTs, uma vez que a Psicologia Social pode ser compreendida como "uma ciência das interações" (Palmonari, 2009, p. 36), uma "disciplina situada na interface do psicológico e do social, do individual e do coletivo" (Jodelet, 2005, pp. 42-43). Nessa vertente, a Psicologia Social é entendida por Jovchelovitch (2004) como a ciência do "entre", e, dessa forma, "o lugar privilegiado do inquérito psicossocial não é nem o indivíduo nem a sociedade mas, precisamente, aquela zona nebulosa e híbrida que comporta as relações entre os dois" (p. 21).

Consideramos essencial utilizar as representações sociais para abordar a interação com moradores das RTs, pois: "Todas as interações humanas, surjam elas entre duas pessoas ou entre dois grupos, pressupõem representações. Na realidade, é isso que as caracteriza" (Moscovici, 2012, p. 40). As representações sociais são criadas a partir das relações sociais estabelecidas nos contextos em que a interação ocorre, com função de auxiliar na compreensão da realidade, ao mesmo 
tempo que orientam as ações nas situações sociais, sendo eficazes no processo de elaboração das condutas:

as representações sociais, enquanto "teorias" socialmente criadas e operantes, se relacionam com a construção da realidade cotidiana, com as condutas e comunicações que ali se desenvolvem, e também com a vida e expressão dos grupos nos seios dos quais elas são elaboradas. (Jodelet, 2005, p. 40)

Além disso, as representações sociais podem ser entendidas como mediações simbólicas que possibilitam a atribuição identitária, respondendo à necessidade de diferenciação intergrupal. Assim, os grupos "estabelecem a sua identidade e sua diferença nas e pelas representações" (Jodelet, 2009, p. 120).

Nesse percurso, também nos apoiamos nas contribuições de Tajfel (1983), que entende a identidade social como "aquela parcela do autoconceito dum indivíduo que deriva do seu conhecimento da sua pertença a um grupo (ou grupos) social, juntamente com o significado emocional e de valor associado àquela pertença” (p. 290).

No campo das relações intergrupais, a consolidação da identidade social positivamente avaliada requer a diferenciação do próprio grupo em comparação a outro grupo colocado em posição inferior, visto que: "A melhoria da posição dum grupo, e a mais forte afiliação dos seus membros que daí resulta, é conseguida, muitas vezes, à custa da utilização da capacidade do grupo para pôr outro grupo em desvantagem" (Tajfel, 1982, p. 157).

Acreditamos que as interações sociais com os moradores das RTs podem estar fundamentadas em representações sociais que favorecem a diferenciação e, por conseguinte, reproduzem a ideia de seu distanciamento como uma necessidade de proteger a identidade social dos habitantes das localidades que recebem RTs. Nesse aspecto: "Esta necessidade é satisfeita pela criação de diferenças intergrupo quando tais diferenças não existem de fato, ou pela atribuição de valor e de realce a quaisquer diferenças existentes" (Tajfel, 1983, p. 313).

\section{Método}

Norteamos os procedimentos metodológicos por meio da pesquisa qualitativa, que visa essencialmente à relação entre os diversos atores sociais, sendo o trabalho de campo uma peça fundamental ao método qualitativo de investigação (Minayo, 2004).

O método qualitativo de pesquisa abarca inúmeras perspectivas de investigação científica, entre elas a etnografia. Dessa forma, partimos de uma perspectiva etnográfica para coletar os dados em campo. Segundo Angrosino (2009), a etnografia "é a arte e a ciência de descrever um grupo humano - suas instituições, seus comportamentos interpessoais, suas produções materiais e suas crenças" (p. 30).

A permanência do pesquisador em campo por um determinado período possibilita a compreensão das relações estabelecidas, ao mesmo tempo que favorece a inserção, familiarizando-se com as pessoas do lugar (Rocha \& Eckert, 2008; Sato \& Souza, 2001).

A utilização da perspectiva etnográfica possibilitou a realização de entrevistas e também a apreensão de informações complementares às entrevistas, provenientes das observações e registros em diário de campo. A coleta de dados foi realizada entre outubro de 2011 e fevereiro de 2012, em dias e horários diversificados.

Os participantes são habitantes de um bairro que recebe três RTs, sendo que alguns participantes trabalham ou possuem comércios no local. A partir de caminhadas pelo bairro, os participantes foram selecionados por conveniência e acessibilidade. Assim, realizamos 24 entrevistas com roteiro semiestruturado explorando as concepções dos participantes sobre os moradores das RTs, bem como, sobre a conversa e os encontros com os moradores nos espaços públicos. Algumas entrevistas foram realizadas com duas ou mais pessoas ao mesmo tempo, no entanto, nenhum participante foi entrevistado repetidamente. Ademais, vale destacar que os nomes dos moradores das RTs mencionados neste artigo pelos participantes foram alterados, a fim de preservar seu anonimato.

O bairro é caracteristicamente um conjunto residencial e conta com poucos estabelecimentos comerciais, dentre os quais, bares, lanchonetes e padaria, além de uma igreja católica e uma pracinha central. Fica localizado em uma zona periférica, a aproximadamente 10 quilômetros do centro da capital, em um município do sudeste brasileiro que compõe a região metropolitana e conta com população média de 350 mil habitantes.

Analisamos os dados com o auxílio de Minayo (2004). Inicialmente, partimos da leitura exaustiva do material, que compreende a transcrição total das entrevistas. Posteriormente, realizamos recortes de partes do texto que se destacavam, e, por fim, agrupamos e organizamos os recortes em temáticas, que subsidiaram os resultados.

De acordo com a Resolução $n^{0} 466 / 2012$, do Conselho Nacional de Saúde, após consentirem em sua participação voluntária, os participantes 
foram esclarecidos sobre os objetivos da pesquisa, a possibilidade de abandonar a entrevista e a garantia do anonimato das informações, entre outros aspectos.

\section{Resultados e discussões}

Apresentaremos e discutiremos os resultados a partir de duas seções principais: na primeira, abordaremos as concepções dos participantes em relação aos moradores das RTs e, na segunda, suas concepções sobre os momentos de conversa e os encontros com os moradores nos espaços públicos do bairro. Ressaltamos que substituímos o nome dos moradores das RTs citados pelos participantes por nomes fictícios para preservar o anonimato.

\section{Os moradores das RTs}

Os participantes relataram que conhecem os moradores das RTs "de vista", sobretudo, a partir da presença destes nos estabelecimentos comerciais da região: "Conheço um que ficava na padaria o dia todo ali". Além deste reconhecimento "de vista", os moradores são conhecidos por apelidos e também pelo próprio nome. Isso pode ser considerado como uma situação favorável aos objetivos da reinserção social, no sentido de que os moradores estariam vivendo em comunidade, no entanto, parcialmente, pois uma comunidade é um lugar "onde a pessoa, além de possuir um nome próprio, isto é, além de manter sua identidade e singularidade, tem possibilidade de participar, de dizer sua opinião, de manifestar seu pensamento, de ser alguém" (Guareschi, 2002, p. 95). Nesse caminho, os participantes citaram os nomes ou apelidos de moradores das RTs com maior interação nos espaços do bairro ou com os quais os participantes estabeleceram algum tipo de ligação:

O Everaldo eu conheço, agora me falha na memória o nome do outro rapaz, ele até puxava da perna... o Robocop! Nossa, os dois são os que a gente mais convivia, agora eu tô lembrando dele contando da história dele, de como aconteceu, passo a passo.

O Marcinho e o Edmilson! O Edmilson não tem problema nenhum, mas não tem onde morar. Não tem família, não tem ninguém. Ele ajuda muito o pessoal ali da casa, ele leva o pessoal prá cortar cabelo, prá fazer barba, é tudo ele. Então o cara já tá socializado, né, mas vai morar aonde?

Conheço sim, o pessoal chama ele de Marcinho, vinha na igreja aqui do lado, na Maranata toda noite. Tem a Jéssica daqui da casa, cresceu comigo, minha infância aqui. A casa dos pais dela era essa aqui de frente pra pracinha e hoje ela mora aqui do lado também.
A inserção das RTs no bairro possibilitou este reconhecimento dos moradores das RTs pelos participantes: o jeito de andar do Robocop que "puxava da perna", as histórias de vida da Jéssica que "cresceu comigo", a autonomia demonstrada pelo Marcinho que "vinha na igreja aqui" e pelo Edmilson que "não tem problema nenhum", mas permanece na RT porque "não tem ninguém".

Pinheiro e Machado (2011) também realizaram pesquisa com moradores das RTs do bairro e observaram que o reconhecimento destes nos espaços públicos, como o exemplo do Robocop, favoreceu a criação de uma relação de proximidade com os habitantes da vizinhança: "Durante uma das caminhadas irrompeu o comentário inusitado - 'Eles me chamam de Robocop!' ... O jeito de andar criou outras histórias, que parecem falar da conexão com algumas pessoas do bairro" (p. 125).

Em outra direção, podemos questionar acerca dos moradores das RTs que não aparecem no relato dos participantes. Se, por um lado, a situação pode parecer favorável à reinserção social dos moradores das RTs a partir de seu reconhecimento na esfera pública, por outro, há um aparente desconhecimento em relação aos outros moradores das RTs que não foram mencionados no relato dos participantes.

Entendemos que as representações sociais desempenham funções específicas e estão relacionadas aos contextos locais em que emergem. Nessa vertente, é possível que representações aparentemente contraditórias coexistam em um mesmo grupo, pois: "As formas de saber se relacionam uma a outra, mas não necessariamente sucedem uma a outra linearmente. Elas necessitam ser entendidas em relação ao contexto em que são usadas e em relação às funções que preenchem" (Jovchelovitch, 2004, p. 27). Nessa esteira, um participante afirmou não haver uma relação de intimidade com os moradores, apesar de conhecer um destes pelo nome e demonstrar certa cordialidade com aqueles que passam pelas proximidades de sua casa:

A gente brinca com eles, mas não tem, assim, intimidade. Mas um a gente chama sempre o nome... Salvador. Uma pessoa, um baixinho, a gente brinca... Então, todos eles passam aqui, os outros a gente não tem intimidade, mas a gente sempre faz contato, oi, bom dia, boa tarde, como é que vai, tudo bem.

Além disso, observamos que poucos moradores das RTs circulam pelo bairro de modo a estabelecer vínculos com os participantes, como revelam os relatos abaixo:

Dos que passa aqui, o Marcinho. Ele para, entendeu, ele tá lá na pracinha, vai na padaria, pede alguma coisa ou pede um cigarro prá quem tá passando. A 
pessoa que é mais espontânea, no caso, seria ele, ele chega, brinca, conversa, os outros são mais fechados, mais retraidos.

Só tinha dois aqui, que era o Everaldo e o Robocop que tinha amizade. E o Marcinho. Que parava, ficava junto, igual, nessa roda, entendeu? E a gente brincava com eles, tal. O resto a gente não tem contato nenhum.

Se, por um lado, alguns moradores das RTs são conhecidos pelo apelido ou pelo nome, por outro, os relatos de que "os outros são mais fechados" e "o resto a gente não tem contato nenhum" demonstram o desconhecimento em relação aos moradores não citados.

\section{A conversa e os encontros com os moradores das} $R T s$

Abordaremos nesta seção as concepções dos participantes a respeito dos momentos de conversa e dos encontros com os moradores das RTs nos espaços públicos do bairro. Os participantes afirmaram que a conversa com os moradores das RTs ocorre, principalmente, quando estes se encontram nos comércios locais: "De vez em quando converso com algum deles, quando eles vêm comprar as coisas aqui, a gente tá batendo um papo". Parece haver iniciativa para o diálogo por parte de alguns moradores das RTs mais espontâneos: "Tinha um ali, esse sempre passava, ele andava só, ele vem na padaria, compra as coisas, ai passava pela gente 'ó minha fotografia', chegava lá mostrava a fotografia".

Os estabelecimentos comerciais, em especial a padaria do bairro, se configuram como lugares favoráveis para a interação dos participantes com os moradores das RTs, possibilitando momentos de diálogo: "Esse menino, ele vinha, a gente conversava com ele, batia papo... parava e conversava! Chegava aqui na padaria, comprava uma coisinha e trazia". A padaria do bairro se constituiu como um espaço importante na promoção de laços afetivos dos moradores com os habitantes da vizinhança, como observado anteriormente por Moreira (2007): "Há uma padaria no andar térreo de uma das casas que apresenta uma via de acesso interessante. Nessa padaria, há uma garrafa de café à disposição da clientela, e sempre existem pessoas conversando em torno do cafezinho" (p. 174).

Conforme Agier (2011), entendemos que o significado de habitar uma casa se associa também à apropriação do espaço público pelo seu morador, uma vez que o autor enfatiza a existência de uma estreita relação entre as esferas pública e privada. Nessa ótica, podemos afirmar que as RTs têm possibilitado que os seus moradores frequentem o espaço público, por meio dos relatos de que estes frequentam a padaria e outros estabelecimentos comerciais e religiosos do local. De forma geral, notamos que a circulação dos moradores das RTs pelos comércios do bairro favoreceu $o$ estabelecimento de vínculos com os participantes, constituindo-se como importante estratégia para sua reinserção social:

Igual quando tinha o bar do bigode aqui, quando o bigode era vivo, o pessoal ia lá comprar algumas coisinhas, cigarro, comprava... o que eles gostavam ia lá comprar. Às vezes tava lá dentro batendo papo, tomando uma cervejinha, alguma coisa, eles passavam e conversavam com a gente.

São situações que ilustram a inserção dos moradores das RTs nos espaços públicos do bairro e demonstram o estabelecimento das interações sociais: "o habitar se revela lentamente e o morador passa a fazer parte do cotidiano da vida do bairro: saber o horário em que o pão sai do forno da padaria; na farmácia, em que o atendente o reconhece pelo nome, pergunta pelos familiares" (Moreira, 2007, p. 170).

A frequência de alguns dos moradores das RTs pelos espaços públicos do bairro, como padaria e bares, possibilitou o reconhecimento social destes moradores e o diálogo com os participantes. Nesse contexto, podemos entender que: "Um dos aspectos mais importantes da vida em comunidade é que ela cria uma esfera pública, isto é, um espaço comum a todos os membros da comunidade onde a vida comunitária se torna visível e conhecida pela comunidade" (Jovchelovitch, 2008, p. 147).

Apesar desta vertente favorável à reinserção social dos moradores das RTs, em alguns momentos do relato dos participantes ficou clara a existência de uma relação de distanciamento. Nesse sentido, observamos que a conversa entre participantes e moradores das RTs se restringe aos encontros de passagem: "A gente não tem, assim, uma relação muito aproximada. A gente passa, oi prá lá, oi prá cá. A gente se esbarra, às vezes a gente conversa, quando pergunta alguma coisa, a gente conversa". Esta situação adquire uma conotação ambígua, pois, por um lado, aparenta ser favorável à reinserção, pelo reconhecimento social dos moradores, mas, por outro, revela uma interação ainda incipiente e a distância. A polaridade "lá" e "cá" evidencia esta diferenciação na relação intergrupal, todavia, foi a partir dessa relação passageira que os participantes estabeleceram laços positivos com os moradores das RTs que circulam pelo bairro: 
Eu passo e falo bom dia, eles falam com a gente. A gente passa a ter uma convivência, pelo menos assim, no cotidiano, trocar uma ideia que a gente acha que é importante, poder interagir com essas pessoas de alguma forma, seja na palavra, um bom dia, um boa tarde.

Mesmo que "na palavra", a interação social de participantes e moradores das RTs parece proporcionar uma troca afetiva favorável à sua reinserção social. Nesse sentido, Moreira e Castro-Silva (2011) ponderam:

E assim, os bons encontros entre as pessoas e o exercício dialógico entre indivíduos livres possibilitam o surgimento de uma relação intensa que pode se configurar como um bom encontro potente para a construção de uma relação de amizade estabelecida na comunidade. (p. 552)

Entretanto, mesmo com essa apreciação favorável, foi igualmente considerável o esforço observado no relato dos participantes em esclarecer a medida desta interação, e às vezes, a própria ausência de interação. Alguns participantes ressaltaram que nunca conversaram, nunca pensaram em conversar ou não possuem o costume de conversar com os moradores das RTs: "Não, não, isso aí, hábito de conversar constante com eles não". Uma participante delineou este distanciamento de forma mais veemente: “Ah, eu não tenho papo pra eles não! Porque eu vejo as meninas na minha rua, mas quando a gente tá ali, que elas descem um pouquinho, a gente mexe com elas, mas logo elas tão dentro de casa”. Os relatos que indicam a criação de vínculos e laços sociais entre participantes e moradores das RTs coexistem com as representações sociais que indicam escasso diálogo na interação, delineando o caráter polissêmico das representações sociais: "A dinâmica da forma representacional lhe permite a variação e a capacidade de conter tantas racionalidades quantas necessárias à variedade infinita de situações socioculturais que caracterizam a experiência humana" (Jovchelovitch, 2004, p. 27).

Os participantes relataram que o diálogo na interação com os moradores das RTs é escasso, uma vez que a circulação destes, quando saem à rua, se restringe a ir à padaria e retornar para a RT, e, além disso, em função de supostos "problemas" relacionados aos moradores que os impossibilitariam para a conversa: "Na verdade, eles quase não conversam. Eles simplesmente saem, vai na padaria, volta, mas não tem diálogo com a gente, devido os problemas deles". Diante disto, nos questionamos em que medida se desenvolve o processo de reintegração à vida comunitária dos moradores das RTs, no momento em que "não tem diálogo" na esfera pública, pois: "É como membros de uma comunidade que nos tornamos nós mesmos, emergimos como atores sociais competentes e aprendemos a falar uma língua... Seria muito difícil, se não impossível, tornar-se pessoa, sem comunidade" (Jovchelovitch, 2008, p. 127).

Os relatos sobre a ausência de diálogo com os moradores das RTs ilustram a dificuldade inerente aos processos de desinstitucionalização. Martins et al. (2013), debatem a complexidade existente na relação social estabelecida com as RTs e afirmam ser "preciso estabelecer relações de convívio com os moradores vizinhos, com o comércio do bairro, e o reconhecimento de trajetos diários pela cidade, gerando, assim, o sentimento de inclusão naquele território" (p. 330).

Contudo, essa aproximação social com a loucura pode incitar mecanismos de separação como forma de defesa identitária. Jodelet (2005) observou em sua pesquisa que a defesa da integridade grupal se constituiu como uma das principais formas de resposta social frente ao convívio com ex-internos de hospitais psiquiátricos. Naquele contexto, foram criadas representações sociais da loucura que possibilitavam o distanciamento simbólico e concreto na relação social com os egressos, constituindo-se como tentativas de defesa da identidade grupal.

A interação com os moradores das RTs pode significar uma ameaça à identidade social de pessoas ou grupos que passam a conviver com as RTs. Dessa forma, a representação social dos moradores como incapazes para o diálogo, em nossa pesquisa, proporciona a distância necessária para a diferenciação intergrupal, sobretudo em um local que possui três RTs. Não obstante, a crença de que os moradores não conversam devido a um problema que é intrínseco a eles acaba servindo para justificar e legitimar a ausência de comunicação dos moradores com participantes, retirando destes a responsabilidade para o diálogo a seguir: "Eles não conversam devido os problemas deles". Em alguns momentos, a ausência de diálogo foi considerada resultante do uso de medicamentos pelos moradores:

Têm alguns que conversam normal. Têm outros já que fala as coisas, mas fala, assim, buscando ao longe, buscando ao vento lá o que ele tem que falar. Não sei se foi por causa dos remédios que ele esqueceu o que ele tem que falar.

Assim, a expressão "buscando ao vento" revela a peculiaridade presente no diálogo com moradores das RTs, provavelmente fugindo do que seria habitual aos participantes. Mas, apesar de tais afirmações, nossos 
participantes ressaltaram que isso não constituiria um impedimento para as trocas sociais, apesar do efeito negativo da medicação a qual estariam submetidos: "Eles são, assim, um pouco limitados, talvez devido aos remédios, eles respondem mais o que você pergunta, eles não perguntam tanto, eles não questionam tanto, são um pouco assim... fechados. Mas respondem se você perguntar, dentro da sua limitação".

A afirmação de que os moradores dialogam "dentro da sua limitação" pode assumir uma função importante para os participantes, entendendo que as representações sociais são produzidas nas relações e possuem funções específicas, estando ligadas ao contexto no qual emergem. As representações sociais "expressam os processos através dos quais uma comunidade produz o sistema de saberes que the confere uma identidade social, uma forma de enfrentar o cotidiano e uma forma de se relacionar com os objetos que o rodeiam" (Jovchelovitch, 1998, p. 80).

A representação social dos moradores das RTs como "um pouco limitados" contribui para a constituição da identidade social dos participantes de nossa pesquisa, na medida em que favorece a diferenciação intergrupal, especialmente em um bairro tão próximo do hospital psiquiátrico e que recebe as RTs, isto é, já marcado por essa associação com questões associadas à loucura.

No terreno das relações intergrupais, é por meio de uma perspectiva comparativa que se estabelece a diferenciação entre grupos, no momento em que se coloca outro grupo em posição inferior ou de desvantagem, possibilitando a constituição de uma identidade social positivamente avaliada de um grupo de referência (Tajfel, 1982, 1983).

Dessa forma, a representação social dos moradores como limitados para o diálogo serviria para realçar a diferenciação intergrupal na relação de participantes e moradores, em resposta à necessidade de preservação da identidade social positivamente avaliada. Todavia, essa representação exclui dos moradores das RTs uma característica fundamentalmente humana, e que é a base das relações sociais, o diálogo:

Nós, como humanos, somos capazes de nos representar dentro de nossas próprias vidas. Somos seres dotados de consciência reflexiva que podemos empunhar ironia e metáfora, criar a tragédia, o sofrimento e, por fim, seres portadores de discurso, de comunicação, sempre endereçados a alguém, a uma pessoa registrada no espaço social. (Bibeau, 2013, p. 2809)

Consideramos necessário abrir um parêntese para destacar um momento ocorrido durante a coleta de dados e registrado em diário de campo, em que foi possível dispor de alguns minutos de diálogo com um morador de RT conhecido como "Marcinho":

\begin{abstract}
Às vezes, eu perguntava as coisas prá ele e ele me respondia; às vezes monossilábico; outras vezes, ele não respondia, e ficava me olhando com um semblante meio que sério. O primeiro destaque é esse: o olhar sério do Marcinho aliado ao seu silêncio ou resposta banal. Como lidar com isso? É tranquilo? As pessoas conseguem lidar com esse tipo de encontro, com os novos e intrigantes moradores daquele bairro? (Diário de campo)
\end{abstract}

Podemos compreender que essa peculiaridade implícita no diálogo com os moradores das RTs pode se constituir como fundamento que embasa a representação da limitação e justifica as ações de distanciamento no contexto da convivência com RTs: "o que a história da loucura nos revela, pondo em questão toda a cultura ocidental moderna, é que o louco é excluído porque insiste no direito à singularidade e, portanto, à interioridade" (Frayze-Pereira, 2006, p. 102).

Mas, se, por um lado, a representação da incapacidade dos moradores das RTs para a conversa produzum distanciamento eproporciona diferenciação intergrupal necessária para a constituição da identidade social de um grupo de referência, por outro, significa um obstáculo a ser superado no campo da reintegração social dos moradores das RTs, pela complexidade que esta interação implica, caracterizada por formas de diálogo pouco convencionais. Problematizar a interação com os moradores das RTs é importante, principalmente diante desta escassa possibilidade de diálogo com habitantes da vizinhança, pois, segundo Jovchelovitch (2008): "Viver entre pessoas de uma maneira humana pressupõe a capacidade de fugir do domínio da mera necessidade e construir um domínio totalmente diferente - o domínio da vida pública em que as pessoas realizam sua capacidade de falar e agir" (p. 149).

\section{Considerações finais}

Neste estudo, abordamos as concepções dos habitantes e comerciantes de um bairro que recebe RTs sobre a interação com moradores das RTs, especialmente no que se refere aos momentos de conversa e aos encontros nos espaços públicos. Utilizamos a Teoria da Identidade Social e a Teoria das Representações Sociais para discutir nossos resultados.

Observamos duas vertentes contraditórias no discurso dos participantes: uma demonstra uma aproximação na interação dos participantes 
com os moradores das RTs e outra aponta para um distanciamento nesta relação. $\mathrm{O}$ conhecimento dos moradores pelo nome ilustra a relação mais próxima entre participantes e moradores, o que podemos considerar como um aspecto favorável aos objetivos da reinserção social. Esse reconhecimento foi possibilitado pela circulação e presença de alguns moradores nos espaços sociais e estabelecimentos comerciais do bairro, favorecendo a criação de vínculos e laços afetivos.

Contudo, essa relação de aproximação com os participantes se restringiu aos moradores das RTs que transitam pela rua e comércios do bairro e apresentam maior espontaneidade para a conversa. Além disso, a interação ocorreu por meio de certa medida, isto é, na passagem, de forma fortuita: "A gente passa, oi prá lá, oi prá cá". Essa medida na interação dos participantes com os moradores das RTs se tornou mais saliente a partir do desconhecimento dos participantes em relação aos outros moradores não citados e que, mesmo quando vistos pelos espaços públicos do bairro, foram considerados como "fechados" ou "retraidos", delineando a ausência de contato com "o resto" dos moradores.

Posteriormente, essa medida observada na relação dos participantes com os moradores acabou por se constituir em distanciamento, demonstrado pelas afirmações dos participantes sobre a ausência de intimidade e interlocução na esfera pública: "Eles quase não conversam". Essa ausência de diálogo nos espaços públicos foi fundamentada por supostos problemas ou limitações dos moradores, às vezes entendidos como originários do uso da medicação.

A análise de nossos resultados com base na TIS e na TRS nos possibilitou afirmar que os esforços empreendidos para preservar a identidade social positivamente avaliada dos participantes podem proporcionar ações de distanciamento social sobre os moradores das RTs. A representação social dos moradores como limitados para o diálogo assume função importante na construção de uma identidade social positivamente avaliada dos participantes, promovendo o contraste necessário para o processo de diferenciação social.

Além disso, a expressão "a gente passa, oi prá lá, oi prá cá" revela a possibilidade de interação social dos participantes com moradores das RTs, mas evidencia que tais encontros são fortuitos, ligeiros e passageiros, sem tanta intimidade. Sabemos que as relações sociais na contemporaneidade se caracterizam por velocidade e transitoriedade. Nesse raciocínio, podemos considerar que os moradores das RTs participam do cotidiano local, pois se encontram de certo modo inseridos nesta rede de relações sociais eventuais. Porém, acreditamos que os moradores necessitam mais do que encontros fugazes, sobretudo por meio do estabelecimento de relações que ultrapassem o habitual "oi prá lá, oi prá cá".

As RTs se constituem como dispositivos que permitem a ampliação das trocas sociais dos moradores, a partir de sua circulação pelos ambientes públicos e comerciais. Mas isso é pouco no que tange à desinstitucionalização, uma vez que consideramos preciso criar maneiras de interlocução com o diálogo que "busca ao vento", possibilitando novas formas de comunicação e maneiras de conviver e interagir com essa narrativa considerada sem sentido aparente. Compreender, em maior medida, a convivência entre moradores e habitantes das vizinhanças das RTs ajuda a pensar em alternativas para ultrapassar os limites dos encontros fortuitos, criando laços consistentes e demorados entre a loucura e a esfera pública.

\section{Referências}

Agier, M. (2009). Antropologia da cidade: lugares, situações, movimentos (G. I. Cordeiro, Trad.). São Paulo: Terceiro Nome.

Angrosino, M. (2009). Etnografia e observação participante (J. Fonseca, Trad.). Porto Alegre: Artmed.

Bibeau, G. (2013). O humano entre a medida e a desmedida: o que são "evidências"? Ciência \& Saúde Coletiva, 18(10), 2808-2812.

Del Giudice, G. (1998). La riforma psichiatrica in itália. Dipartimento di Salute Mentale Trieste.Trieste: Letteratura. Acesso em 30 de agosto, 2013, em http://www. triestesalutementale.it/letteratura/testi/8rifpsi.htm

Frayze-Pereira, J. A. (2006). O que é loucura (10 ed.). São Paulo: Brasiliense.

Guareschi, P. A. (2002). Relações comunitárias, relações de dominação. In R. H. F. Campos (Org.), Psicologia Social Comunitária: da solidariedade à autonomia ( $7^{\mathrm{a}}$ ed., pp. 8199). Petrópolis, RJ: Vozes.

Jodelet, D. (2005). Loucuras e representações sociais (L. Magalhães, Trad.). Petrópolis, RJ: Vozes.

Jodelet, D. (2009). Recentes desenvolvimentos da noção de representações nas ciências sociais. In A. M. O. Almeida \& D. Jodelet (Orgs.), Representações sociais: interdisciplinaridade e diversidade de paradigmas (pp. 105122). Brasília, DF: Thesaurus.

Jovchelovitch, S. (1998). Re(des)cobrindo o outro - para um entendimento da alteridade na Teoria das Representações Sociais. In A. Arruda (Org.), Representando a Alteridade (pp. 69-82). Petrópolis, RJ: Vozes.

Jovchelovitch, S. (2004). Psicologia social, saber, comunidade e cultura. Psicologia \& Sociedade, 16(2), 20-31.

Jovchelovitch, S. (2008). Contextos do saber: representações, comunidade e cultura (P. Guareschi, Trad.). Petrópolis, RJ: Vozes.

Lei 10.216, de 06 de abril de 2001. (2001). Dispõe sobre os direitos e a proteção de pessoas acometidas de transtornos mentais e redireciona o modelo assistencial em saúde mental. Brasília, DF: Ministério da Saúde. 
Martins, G. C. S., Peres, M. A. A., Oliveira, A. M. B., Stipp, M. A. C., \& Almeida, A. J. (2013). O estigma da doença mental e as residências terapêuticas no município de Volta Redonda-RJ. Texto \& Contexto - Enfermagem, 22(2), 327 334.

Minayo, M. C. S. (2004). O desafio do conhecimento: pesquisa qualitativa em saúde ( $8^{\mathrm{a}}$ ed.). São Paulo: Hucitec.

Ministério da Saúde. (2011). Saúde Mental no SUS: as novas fronteiras da Reforma Psiquiátrica. Relatório da gestão 2007 - 2010. Brasília, DF: Autor. Acesso em 30 de agosto, 2013, em http://portal.saude.gov.br/portal/arquivos/pdf/ gestao2007_2010.pdf

Moreira, M. I. B. (2007). Se esta casa fosse minha: habitar e viver na cidade a partir de uma residência terapêutica. Tese de Doutorado, Programa de Pós-graduação em Psicologia, Universidade Federal do Espírito Santo, Vitória.

Moreira, M. I. B. \& Castro-Silva, C. R. (2011). Residências terapêuticas e comunidade: a construção de novas práticas antimanicomiais. Psicologia \& Sociedade, 23(3), 545-553.

Moscovici, S. (2012). Representações sociais: investigações em psicologia social (P. Guareschi, Trad., $9^{\mathrm{a}}$ ed.). Petrópolis, RJ: Vozes.

Palmonari, A. (2009). A importância da teoria das representações sociais para a psicologia social. In A. M. O. Almeida \& D. Jodelet (Orgs.), Representações sociais: interdisciplinaridade e diversidade de paradigmas (pp. 35 50). Brasília, DF: Thesaurus.

Pinheiro, J. A. C. \& Machado, L. D. (2011). Experiência clínica por meio de imagens cartográficas. Psicologia \& Sociedade, 23(N. spe.), 120-128.

Portaria n. 106, de 11 de fevereiro de 2000. (2000). Institui os Serviços Residenciais Terapêuticos no âmbito do SUS. Brasília, DF: Ministério da Saúde.

Portaria n. 3.090, de 23 de dezembro de 2011. (2011). Estabelece que os serviços residenciais terapêuticos (SRTs) sejam definidos em tipo I e II e dá outras providências. Brasília, DF: Ministério da Saúde.

Rocha, A. L. C. \& Eckert, C. (2008). Etnografia: saberes e práticas. Iluminuras, 9(21). Acesso em 30 de agosto, 2013, em http://seer.ufrgs.br/index.php/iluminuras/article/ view/9301/5371

Rotelli, F., Leonardis, O., \& Mauri, D. (1986). Deistituzionalizzazione, un'altra via. Dipartimento di Salute Mentale Trieste.Trieste: Letteratura. Acesso em 30 de agosto, 2013, em http://www.deistituzionalizzazionetrieste.it/letteratura/Letteratura/index.php
Resolução n. 466, de 12 de dezembro de 2012. (2012). Regulamenta pesquisas em seres humanos no Brasil e da outras disposições. Conselho Nacional de Saúde. Brasília, DF: Ministério da Saúde. Acesso em 30 de agosto, 2013, em http://conselho.saude.gov.br/resolucoes/2012/ $\underline{\text { Reso466.pdf }}$

Sato, L. \& Souza, M. P. R. (2001). Contribuindo para desvelar a complexidade do cotidiano através da pesquisa etnográfica em psicologia. Psicologia USP, 12(2). 29-47.

Tajfel, H. (1982). Grupos humanos e categorias sociais I. Lisboa: Livros Horizonte.

Tajfel, H. (1983). Grupos humanos e categorias sociais II. Lisboa: Livros Horizonte.

Wachs, F., Jardim, C., Paulon, S. M., \& Resende, V. (2010). Processos de subjetivação e territórios de vida: o trabalho de transição do hospital psiquiátrico para serviços residenciais terapêuticos. Physis: Revista de Saúde Coletiva, 20(3), 895912.

\section{Agradecimento}

Pesquisa financiada pela Coordenação de Aperfeiçoamento de Pessoal de Nível Superior CAPES, por meio da concessão de bolsa de doutorado.

Submissão em: 09/06/2014

Revisão em: 19/02/2015

Aceite em: 24/02/2015

Pedro Machado Ribeiro Neto é doutor em Psicologia Universidade Federal do Espírito Santo - UFES. Estágio pós-doutoral no Programa de Pós-Graduação em Psicologia da Universidade Federal do Estado do Espírito Santo. Endereço: Universidade Federal do Espirito Santo. Av. Fernando Ferrari, $n^{\circ}$ 514. Prédio Professor Lídio de Souza. Campus Universitário de Goiabeiras - UFES. CEP 29075-910. Vitória/ ES, Brasil. E-mail: mrn.pedro@gmail.com

Luziane Zacché Avellar é professora doutora do Programa de Pós-Graduação em Psicologia da Universidade Federal do Espírito Santo. E-mail: luzianeavellar@yahoo.com 